\title{
Tjalling H. F. Halbertsma. Early Christian Remains of Inner Mongolia: Discovery, Reconstruction, and Appropriation
}

\section{Florence Jullien}

\section{(2) OpenEdition \\ 1 Journals}

Édition électronique

URL : http://journals.openedition.org/abstractairanica/40831

DOI : 10.4000/abstractairanica.40831

ISSN : 1961-960X

Éditeur :

CNRS (UMR 7528 Mondes iraniens et indiens), Éditions de l'IFRI

\section{Édition imprimée}

Date de publication : 1 décembre 2013

ISSN : 0240-8910

Référence électronique

Florence Jullien, « Tjalling H. F. Halbertsma. Early Christian Remains of Inner Mongolia: Discovery, Reconstruction, and Appropriation », Abstracta Iranica [En ligne], Volume 32-33 | 2013, document 324, mis en ligne le 01 juillet 2016, consulté le 26 septembre 2020. URL : http://journals.openedition.org/ abstractairanica/40831 ; DOI : https://doi.org/10.4000/abstractairanica.40831

Ce document a été généré automatiquement le 26 septembre 2020.

Tous droits réservés 


\title{
Tjalling H. F. Halbertsma. Early Christian Remains of Inner Mongolia: Discovery, Reconstruction, and Appropriation
}

\author{
Florence Jullien
}

\section{RÉFÉRENCE}

Tjalling H. F. Halbertsma. Early Christian Remains of Inner Mongolia: Discovery, Reconstruction, and Appropriation. Leiden, Brill, 2008, xxx + 356 p.

1 S'intéressant à la plus ancienne présence chrétienne en Mongolie intérieure, l'A. suppose qu'il s'agissait d'Öngüts nestoriens utilisant l'écriture et les langues oïghoure, chinoise et syriaque. Le matériau archéologique et épigraphique est ici réexaminé afin de reconstituer la culture de ces communautés sous les Mongols. Exposé est fait des découvertes de pierres gravées, dont certaines sont publiées pour la première fois (chap. 2), ainsi que des tombes décorées à inscriptions de la région de Hohhot, datées des XIII et $\mathrm{XIV}^{\mathrm{e}}$ siècles (chap. 3); l'usage de l'écriture syriaque restait cependant l'apanage d'une élite car peu d'Önguts la pratiquaient. La dernière partie (chap. 4) est plus ethnographique, montrant comment des groupes variés comme les Mongols ou les Hans chinois se sont appropriés des matériaux nestoriens, vraisemblablement aussi à la faveur de l'ambiguïté du symbolisme des représentations picturales. Certaines décorations funéraires témoignent d'influences culturelles multiples, intégrant croix, fleurs de lotus, dragons et imagerie taoïste, mais aussi des motifs inspirés du monde islamique. L'ouvrage se termine avec environ quarante pages de bibliographie, un index et des planches d'illustration. Mentionnons une carte qui permet de localiser les principaux lieux où furent retrouvés des vestiges archéologiques de la communauté nestorienne - au total 21 sites. Ce livre constitue une avancée importante pour mieux 
connaître l'héritage transmis aux Mongols par les chrétiens venus d'Iran et l'histoire culturelle de l'empire mongol.

AUTEURS

FLORENCE JULLIEN

EPHE, Paris 